\title{
Long-term Outcomes of Early Childhood Science Education: \\ Insight from a Cross-national Comparative Case Study on Conceptual Understanding of Science
}

\begin{abstract}
The purpose of this research was to explore the long term outcomes of either participating or not participating in early childhood science education on Grade 6 students' conceptual understanding of science. The research is situated in a conceptual framework that evokes Piagetian developmental levels as both potential curriculum constraints and potential models of efficacy. The research design was a multiple case study of Grade 6 children from three schools in China $(n=140)$ who started formal science education in the third grade, and Grade 6 children from three matched schools in Australia $(n=105)$ who started learning science in kindergarten. The students' understanding was assessed by a science quiz and in-depth interview. The data showed that participating children from the high socio-economic schools in China and Australia had similar understandings of science. Divergence between the medium and low socio-economic schools, however, indicated that the grounding in early childhood science education in Australia may have placed these children at an advantage. Alternative explanations for the divergence including the nature of classroom instruction in the two countries are discussed.
\end{abstract}

Key words: comparative study, conceptual understanding, elementary children, science education

Tao, Y., Oliver, M., \& Venville, G. (2012). Long-term outcomes of early childhood science education: Insights from a cross-national comparative case study on conceptual understanding of science. International Journal of Science and Mathematics Education, 10(6), 1269-1302. 


\section{Introduction}

Science education for children in the early years of elementary school is a conundrum in a number of ways. In this critical period of education, the focus often is on literacy and numeracy and this leaves little room in the curriculum for the teaching and learning of the many other components of a comprehensive education such as science (Appleton, 2007; Greenfield et al., 2009). Other problems revolve around elementary teachers who have been well documented as feeling under qualified and lacking in the science knowledge and the pedagogical knowledge needed to teach science in an effective way (Appleton, 2007). As a consequence, they have considerable avoidance strategies such as teaching as little science as possible, focusing on topics about which they have more confidence, relying on textbooks, and avoiding practical work (Harlen, 1997). Further still, it has been found that while science is taught in elementary schools only once or twice a week, student learning is best supported with more frequent exposure to science concepts and ideas (Nuthall, 1999).

Despite these problems and issues, many countries have a science curriculum for children from the first years of school and invest considerable resources in the support of elementary science instruction including professional learning for teachers and educational resources. These countries include England, Germany, Korea, Ghana, and Turkey as well as a considerable number of other developed and developing countries (Mullis et al., 2008). In the United States, the Californian Department of Education Curriculum for Kindergarten through Grade 6 in public schools has seven areas of learning including science, "including the biological and physical aspects, with emphasis on the processes of experimental inquiry and on the place of humans in ecological systems" (California Department of Education, 2011, p. iii). The highlight of the conundrum of early childhood science education is that three of the four top performing countries of the 36 that participated in the Year 4 Trends in Mathematics and Science Study (TIMSS) science test in 2007, Singapore, Hong Kong SAR, and Japan, all do not have a science curriculum prior to Grade 3 (Mullis, et al., 2008). Singapore's curriculum acknowledges that while there is no formal science for young children in schools in this country, science is taught and learned indirectly through language and other activities (Quek et al., 2008). In addition, Chinese Taipei, which came second on the TIMSS Year 4 science international ranking, has General Studies Curriculum in stage 1 (Grades 1-2), in which science and technology are integrated with social science, art, and humanities (Department of Elementary Education, 2008). 
China and Australia have different approaches to elementary science education that provides contrasting and interesting contexts for our research on early childhood science education. In China, elementary children do not have any formal science instruction until they are in the third grade. The theoretical rationale for this approach presented by Chinese curriculum developers and researchers revolves around the Piagetian stage theory (Ding, 1984; Yang, 2004; Yu, 1997; Zhong, 2002; Zhuang, 2001). A similar approach has been adopted in Chinese Taipei, where the curriculum developers emphasize that at the primary level, science content knowledge and learning processes should be organized in accordance with children's cognitive development and competence (Department of Elementary Education, 2008). In contrast with China, children in Australia participate in a formal science curriculum from kindergarten (4 year olds) throughout the elementary school years. The rationale for such an approach also focuses on the developmental nature of learning, but from an efficacy perspective rather than a constraint perspective (Metz, 1995). For example, in the Western Australian Curriculum it states that: "During the early childhood years, a rich, experiential curriculum will enable young children to develop a repertoire of encounters with, and knowledge about, their world that can be built on in the future" and "curriculum experiences should be designed to give young children frequent opportunities to begin exploring concepts like these, which provide the foundation for later understandings" (Curriculum Council Western Australia, 1998, pp. 231-232). Anning, Cullen and Fleer (2009) support this approach and claim that researchers and teachers in Australia are looking for insights into dealing with the limitations of current theories and practices in early years education, "limitations inherent in the interpretations and developments of Piaget's theories" (p. 3).

A recent curriculum reform agenda in China provides the impetus for the current research (Wei, 2008a, 2008b). There is growing enthusiasm to introduce science education in early childhood (Chen, 2004a, 2004b). The research presented in this paper was preceded with an initial study that involved a comparative case study of Chinese and Australian third graders with the purpose of ascertaining whether the three years of early childhood science curriculum in Australia makes an immediate difference to the students' conceptual understanding of science (Author, in press-b). The quantitative and qualitative findings revealed that despite the considerable differences in science curriculum, as well as considerable differences in language and culture, the third graders from case study schools of similar socio-economic status in China and Australia had similar conceptual understandings of life science, Earth science, and physical science. Independent sample $t$ tests of science quiz 
mean scores between paired schools in the two countries indicated no statistically significant difference (Table 1). Similarly, a recent analysis of data from 8,642 children in the United States from the Early Childhood Longitudinal Study-Kindergarten cohort (ECLS-K) found that neither the frequency and duration of kindergarten science teaching or the children's engagement with science activities was a significant predictor of children's end of kindergarten science achievement scores (Saçkes, Trundle, Bell, \& O’Connell, 2011).

Insert Table 1 about here

One of the questions that immediately arose from the findings of the initial study with third grade children and other research was: What happens as the children continue through their elementary education? The study reported in this paper was designed to investigate this question, in particular, we were interested to know whether the grounding in early childhood science education in Australia would place children at an advantage in their science understanding as they reach the end of elementary school, or whether the differences between sixth grade Chinese and Australian children would remain negligible.

\section{Curriculum and Pedagogy in China and Australia}

Appleton (2007) explains that in many countries, science in the elementary school is a relatively recent addition to the curriculum and that prior to World War II, science was essentially nature study. This was the case in both China and Australia. In China, science educational ideology was first imported from the West at the beginning of the twentieth century, and since that time elementary science education has gone through considerable changes (H. Li, 2004; Liu, 1998; Qu \& Wang, 2000). In particular, 'nature study' first became 'science education' with the introduction of a Chinese national curriculum in 2001 (Ministry of Education, 2001). An overview of the history and current elementary science curriculum is provided in Author (in press).

Investigations of the implementation of elementary science curriculum in the past decade (e.g. Cao, 2005; Hao, 2002; Hu, Han, \& Liu, 2007) provide evidence that in China, more than 70 percent of elementary schools recognize the importance of science education and, on average, two teaching hours per week are allocated to science from third grade to sixth grade. The basic instructional methods include experimentation, observation, lecturing, and demonstration. Due to large class sizes (40 to 50 students), whole-class lecturing remains a common teaching method in China and hands-on activities, while practiced, are mainly 
teacher-directed. Textbooks are widely used in science teaching as the predominant source for lesson preparation, science activity organization, and student evaluation.

In Australia, science has been an official component of the elementary curriculum in all states since the late 1960s (Fensham, 1999). Due to influence from the United States and the United Kingdom, considerable changes took place in Australian science curricula across all levels of schooling in the late 1990s (Goodrum, Hackling, \& Rennie, 2001). While each of the Australian states currently has their own curriculum, a national Australian Curriculum from Kindergarten to Grade 10 will be introduced in 2012 (Australian Curriculum Assessment and Reporting Authority, 2011). A more detailed account of the Australian science curriculum is provided by Author (in press-b).

Previous investigations of Australian elementary science teaching and learning practices (Aldridge, Fraser, \& Huang, 1999; Australian Science Technology and Engineering Council, 1997; Lokan, Hollingsworth, \& Hackling, 2006; Thomson, 2006) revealed that about four to five percent of weekly teaching time is allocated to science, in which 40 percent of the time is devoted to life science, 30 percent to Earth science, and 20 percent to physical science. Moreover, elementary science in Australia is generally taught in a student-centered and activity-based manner. Due to comparatively small class sizes (20-30 students), 90 percent of science lessons in Australian elementary schools include teacher-guided practical activities. Teachers have the freedom to decide how to deliver the content of the curriculum and only 31 percent of teachers reported the use of textbooks in science class (Lokan, et al., 2006).

\section{Research on Children's Conceptual Understanding of Science in China and Australia}

In China, there is comparatively little research on elementary children's understandings of basic science concepts, though this research has gained popularity in recent years. From the perspective of Piaget's stage theory and cognitive development, researchers from teachers' colleges and educational research institutes have conducted case studies of elementary and pre-school children's understandings of life and aging (L. J. Zhang \& Fang, 2005a, 2005b; Zhu \& Fang, 2005), floating and sinking (H. J. Luo, 2006), lever balance (Q. M. Zhang, 2006), force and motion (Luo, Wang, \& Liang, 2009; Xiang, 2006), expansion and contraction (Y. W. Luo, 2006), pressure (F. G. Li, 2007), and friction (Wan, 2007). In these recent studies, researchers compared elementary children, who have never received formal instruction on the above concepts, with early secondary children and attempted to identify the difficulties children may meet while developing understanding during instruction. The main 
themes that emerged from these studies are that children's understandings of a certain concept depends on their familiarity with the context and their own experience and it is not advisable to introduce children to abstract concepts or unfamiliar contexts before they enter the concrete-operational stage (Xiang, 2006). This theme is consistent with the current approach in China of not having a formal science curriculum until third grade. This body of literature is somewhat consistent with the 'developmental constraints' model described by Metz (1995). While the research acknowledges the importance of prior knowledge and context for learning, it focuses on the idea that students' developmental level will limit their participation in and learning of science.

In contrast with the literature from China, there is a significant body of research on elementary children's ideas about science in Australia. This research tends to focus on the alternative conceptions that interfere with children's learning across a range of science topics, such as floating and sinking (Moore \& Harrison, 2004), heat and temperature (Harrison, Grayson, \& Treagust, 1999), the Moon (Author, 2007b; Hickey, 2007), evaporation (Campbell \& Tytler, 2007), magnetism (Anderson, Lucas, \& Ginns, 2000), electrical circuits (Fleer, 1994; Georghiades, 2006), and living and non-living things (Author, 2007c). This research generally documents children's understandings of abstract concepts in a specific science domain. Basic research methods utilized include class observation, pre-instructional and post-instructional interviews, and discourse analysis. A number of 'conceptual change' approaches to science teaching and learning have been described and studied, most of which are based on the ideas of alternative conceptions (Author, 2005; Baddock \& Bucat, 2008; Moore \& Harrison, 2004), conceptual restructuring (Baddock \& Bucat, 2008), and representational modes (Campbell \& Tytler, 2007). All conceptual change approaches to teaching and learning involve exploring and challenging children's prior ideas, establishing the science ideas, and extending these ideas to a range of phenomena (Campbell \& Tytler, 2007). There also has been considerable research in recent years on other aspects of children's learning in science, including reasoning, motivational factors, children's views of themselves as learners and creative thinking (Author, 2007a). Unlike the research conducted in China, the body of research from Australia is more consistent with the 'efficacy model' of development (Anning, Cullen \& Fleer, 2009; Metz, 1995) because the notion of what children can do with appropriate instruction is explored.

\section{Nationwide Surveys of Science Understanding in China and Australia}


In 2001, the Chinese Primary Science Curriculum Board, under the commission of the Ministry of Education, carried out a nation-wide science literacy survey with 1432 Grade 6 children from public schools in the eastern, central, western, and the capital city areas. Data about children's understandings of basic science concepts, competence of science skills, and attitudes towards science were collected. The survey reported that children's science literacy varied considerably depending on areas and ethnicities, with children from the eastern provinces of China achieving 20 percent higher science literacy scores than other areas (Fan \& Zhao, 2002).

In 1991, the Australian Science Teachers' Association conducted a nation-wide science literacy survey among 1161 twelve-year old children from government, independent, and Catholic elementary schools in high SES, medium SES, and low SES areas in each state. Children's overall level of science understandings, correlations between their understandings, and gender, location of school, type of school, and family social-economic status were investigated (Pattie \& Groves, 1993). The survey revealed that the science understanding of most children was at a basic level and there was no overall difference in performance between males and females, nor between the children in high SES, medium SES, and low SES schools (Pattie \& Groves, 1993). However, detailed analysis of results from the Trends in Mathematics and Science Study (TIMSS) indicated a large gap between the scores of students from remote schools and those from metropolitan schools (Thomson, Ainley, \& Nicholas, 2007; Thomson \& Fleming, 2004; Thomson, Wernert, Underwood, \& Nicholas, 2008). In addition, studies of Grade 10 students' performance in the Programme for International Student Assessment (PISA) revealed that the average score of students attending schools in remote areas was significantly lower than those attending schools in metropolitan areas (Thomson \& De Bortoli, 2008). Mainland China is yet to participate in either TIMSS or PISA.

\section{Method}

\section{Purpose and Research Questions}

The purpose of this research was to compare Chinese and Australian 6th graders' conceptual understanding of science, thus exploring the long term outcomes of early science curricula on children's science learning. The last term of 6th grade was considered the appropriate time to conduct the research because the children are at the end of their elementary education, however, children in Australia have participated in seven years of formal science instruction, 
but children in China have only participated in four years of formal science instruction. The research questions were:

(1) What are Chinese 6th graders' conceptual understandings of science?

(2) What are Australian 6th graders' conceptual understandings of science?

(3) How do Chinese and Australian 6th graders' conceptual understandings of science compare?

(4) To what extent did the early years of science education put the Australian 6th graders at an advantage in their science learning?

\section{Research Design}

The design of the research was a multiple case study (Yin, 2003) and the data were collected through a mixed methods approach (Creswell, 2003). According to Yin (2003) and Punch (2005), a multiple case study contains more than a single case that provides something akin to "multiple experiments" (Yin, 2009, p. 38). The multiple cases facilitate "analytic generalization, in which previously developed theory is used as a template with which to compare the empirical results of the case study" (Yin, 2009, p. 38). The multiple comparative case study design was selected in order to allow in-depth exploration of elementary children's conceptual understandings of science in Chinese and Australian school contexts and, in turn, give insight into the impact of the contrasting curricular policies and the different interpretations of developmental theory underpinning those policies.

\section{Participants}

The Chinese participants were 140 sixth graders (mean age $=12.1$ ) from Hunan Province, central south China. Of these, 46 children were from an elementary school with high socioeconomic status (C1), 44 children were from a medium SES school (C2) and 50 children were from a low SES school (C3). The Australian participants were 105 sixth graders (mean age $=11.5)$ from Western Australia. Of these, 31 children were from a high SES school (A1), 34 were from a medium SES school (A2) and 40 were from a low SES school (A3). The socio-economic status of the three Australian schools was determined through a metric called Index of Community Socio-Educational Advantage (ICSEA) that is available from the federal government's 'My School' website (http://www.myschool.edu.au/SchoolSearch.aspx). In China, due to the lack of a similar metric, the principal of each case school was asked to complete a questionnaire about the school's demographic characteristics, resources and environment. The questionnaire was developed from TIMSS 2007 School Questionnaire 
(Grade 4). The socio-economic status of the three Chinese schools was estimated through the principals' reports and school observation. The case study schools used for the data collection reported in this paper are the same schools used for previously reported research conducted with the third grade children (Author, in press-b).

The paired schools also were matched for a number of other important variables. Both high SES schools, C1 and A1, are fully government funded and situated next to the campus of a prestigious university in a capital city. Children attending both schools are mainly from the university academic's families. Students and teachers in both schools had considerable access to facilities that support education such as museums, municipal libraries, science centers, and cultural and international events. Both medium SES schools, C2 and A2, are government funded with a small financial contribution from the students' parents. The financial contribution from parents results in both schools being well resourced and principals of both schools reported active participation and interest from parents in the students' education. Both low SES schools, C3 and A3, are fully government funded. Most children attending these schools lived in the immediate locale and their parents generally had working class occupations such as farmers or factory workers. Principals of both schools reported that children generally came from comparatively poor families and the schools experienced associated issues such as difficulty of teacher recruitment and lack of access to resources.

\section{Instruments}

The quantitative data were collected by a science quiz, which was developed from the past Trends in Mathematics and Science Study (TIMSS) science released items and administered to the 6th grade children in China and Australia to determine their general understanding of science. The science quiz consisted of 12 multiple choice items, three items in each content domain of life science, Earth science, and physical science. The first four items tested children's classification of living things and non-living things, their understanding of heredity and plant structure. Items 5-8 tested children's conceptual understanding of the Earth's structure, its motion in the solar system, and gravity. The last four items tested the children's reasoning about floating and sinking. Teachers and planning documents in each case school were consulted to check that the relevant science content and topic areas assessed by the quiz were included in the curriculum and were taught to students. The English version of the TIMSS test was available from the TIMSS official website (http://timss.bc.edu/). The Chinese version of the TIMSS test, released by Science Education Center of National Taiwan 
Normal University (http://www.sec.ntnu.edu.tw), was modified to use the simplified Chinese characters that are standard in mainland China.

The qualitative data were collected by face-to-face interviews. In each case study school, six to eight children representing high, average, and low achievement on the science quiz participated in an in-depth interview on their conceptual understandings of scientific phenomena. In all, 20 Chinese 6th graders and 18 Australian 6th graders participated in the interview. The interview protocol included questions about living things and nonliving things that followed the protocol established by White and Gunstone (1992); questions about the shape of the Earth, day and night cycle, main cause of seasons, and gravity that followed the protocol developed by Vosniadou and Brewer (1992, 1994); and questions about objects' floating and sinking that followed the protocol developed by Piaget (1930). In China, the interviews were conducted in Mandarin and in Australia, the interviews were conducted in English by the first author. The interviews were conducted with pairs of students to help them relax and to facilitate the conversation style of the interview. All interviews were recorded and fully transcribed.

\section{Data analysis}

Scoring of the science quiz involved allocating one point for the correct answer for each item. The maximum score for the quiz was 12 and the minimum was zero. All quiz data were entered into Statistical Package for the Social Sciences (SPSS) software. Descriptive statistics were generated for each case, interpreted and compared with the available international data. Individual case reports were prepared and provided to the principals of each case study school. This paper presents the cross case analysis that initially involved conducting independent sample $t$ tests with $95 \%$ confidence interval to compare the performance of the children on the science quiz between paired schools, effect sizes were calculated and were indicated by Cohen's $d$. Cohen (1988) suggested that a $d$ of .20 reflects a small effect size, a $d$ of .50 medium, and a $d$ of .80 a large effect size. One-way between groups Analysis of Variance (ANOVA) was used to compare the mean test scores among case study schools within China and Australia (Allen \& Bennett, 2008). The quantitative data from individual case studies as well as the cross case comparisons were scrutinized for patterns. This was followed by an exploration of the qualitative interviews for evidence that further explained the patterns in the quantitative data.

\section{Research Rigor}


TIMSS Science assessed children's general understanding of life science, physical science, and Earth science and their cognitive dimensions, and processes including knowing, applying, and reasoning. The TIMSS Science assessment framework was a product of an extensive collaboration of science educators and experts from more than 60 countries, involving input from the TIMSS National Research Coordinators, reviewing by the TIMSS Science and Mathematics Item Review Committee (SMIRC), and further updating by the International Association for the Evaluation of Educational Achievement and TIMSS technical groups to maintain the validity and reliability of the assessment (Olson, Martin, \& Mullis, 2008). TIMSS Science adopted two question formats: multiple choice and constructed response. A pilot study with a small number of Grade 6 children indicated that the children had difficulty explaining phenomena or interpreting data in clear and concise written language. Therefore, only multiple choice questions were adopted for the science quiz in this study. In order to ensure the validity of the quantitative data and to enable a more in-depth exploration of the children's understanding of science, qualitative interviews also were conducted. The combination of quantitative survey and qualitative interview enhanced the rigour of the research (Creswell, 2003) and provided both broad and in-depth information about the participating children's conceptual understandings of science.

\section{Findings}

In this section, the quantitative findings from the science quiz including comparisons between paired schools from China and Australia and comparisons of schools within each country are presented. This is followed by a more in-depth examination of the quantitative and qualitative data on students' conceptual understanding in each conceptual area of life science, Earth science, and physical science.

\section{Science Quiz}

The results of the science quiz showed that, in both countries, the schools with the high socioeconomic status (SES) had the highest mean scores, followed by the schools with medium SES, and then the schools of low SES. The mean scores and $t$ test results are presented in Table 2, and the comparison between similar SES schools in China and Australia can be seen in Figure 1.

Insert Table 2 and Figure 1 about here. 
The independent sample $t$ test between mean science quiz scores of the two high SES schools, C1 $(\mathrm{n}=46)$ and A1 ( $\mathrm{n}=31)$ was not statistically significant, $p=.885$, two-tailed, $d=$ 0.03. The $t$ tests between the medium SES schools C2 $(\mathrm{n}=44)$ and A2 $(\mathrm{n}=34)$, and the low SES schools C3 $(n=50)$ and A3 $(n=40)$, showed that A2 had a mean score 1.29 points higher than $\mathrm{C} 2(p=.003)$, and A3 had a mean score 0.95 points higher than $\mathrm{C} 3(p=.018)$. Both differences were statistically significant and the effect sizes were medium, $d=0.69$ and $d=$ 0.51 respectively.

The ANOVA indicated that the variation in science quiz scores between the case study schools within China was statistically significant, $F(2,137)=19.08, p<.001, \eta^{2}=.218$. Post hoc analyses with Benferroni (using an $\alpha$ of .05) revealed that the high SES school, C1 $(M=$ $9.89, S D=1.72$ ) had a significantly higher mean quiz score than the medium and low SES schools, C2 $(M=8.27, S D=1.98)$ and C3 $(M=7.60, S D=1.86)$. There was no significant difference in mean science quiz scores between the medium and low SES schools, C2 and C3.

Similarly, within the Australian case studies, the ANOVA was statistically significant, $\mathrm{F}(2,102)=6.11, \mathrm{p}<.01, \eta^{2}=.107$. Post hoc analyses with Benferroni (using an $\alpha$ of .05) revealed that the high and medium SES schools, A1 $(M=9.84, S D=1.29)$ and A2 $(M=9.56$, $S D=1.69)$, had significantly higher mean scores than the low SES school, A3 $(M=8.55, S D$ = 1.87). The mean quiz scores for A 1 and A2 were not significantly different.

In summary, the results of the science quiz showed that in both countries, the schools of high socio-economic status ( $\mathrm{C} 1$ and A1) had the highest mean score, followed by the schools of medium socio-economic status (C2 and A2) and then the schools of low socio-economic status (C3 and A3). This pattern was consistent with our previous comparative case study conducted in the same schools of Chinese and Australian third graders' conceptual understanding of science (Author, in press-b). An inconsistent finding, however, was that while the two high SES schools did not have significantly different quiz scores, the medium and low SES schools in China had significantly lower science quiz scores compared with their Australian counterparts. This divergence at medium and low SES can clearly be seen in Figure 1. In the following sections we break down the quiz responses into the conceptual areas of life, Earth and physical science and draw on the interview data to more deeply examine the conceptual understanding of the students.

\section{Children's Understanding of Life Science}

Quiz items 1 to 4 probed the participating children's understanding of life science. The percent correct response for quiz items 1 to 4 in all six cases are presented in Table 3 . The 
data from these items suggest that sixth graders from the Australian case studies were more likely to respond correctly to these four items compared with their Chinese counterparts. Divergence can be seen between the two countries with the low SES school children tending to not perform as well on quiz items 3 and 4 that focused on inheritance and plant structure.

\section{Insert Table 3 about here}

The majority of participating Grade 6 children from both countries selected correct responses to quiz items 1 and 2, which focused on the types, characteristics, and classification of living things. Every child from both the Australian and Chinese high socio-economic schools ( $\mathrm{C} 1$ and $\mathrm{A} 1)$ selected correct responses to these two items. Further, the percent correct response in all six cases on quiz item 1 was higher than the TIMSS 1995 international average $(74 \%)$ for the upper grade (Grade 8). Overall, the results from these two quiz items suggested that sixth graders from all six case study schools could distinguish living things from nonliving things. During the in-depth interviews on living and nonliving things, children from both countries commonly used movement, growth, having cells, organs and blood, having babies, a need for food, and making noise as reasons for attributing life to animals such as a cat and bird. Children from both countries mentioned breathing, growth, death, and the intake of nutrients and water from the soil for attributing life to plants such as trees, flowers, and grass. More Australian children, however, explained scientific ideas that plants breathe the "opposite way" to humans or animals. For example:

$\begin{array}{ll}\text { Interviewer } & \text { Why do you think trees, grass, and flowers are living? } \\ \text { Student }^{\mathrm{A} 3} & \text { Well, trees are living because they breathe in carbon } \\ & \text { dioxide and breathe out oxygen. And they also grow. }\end{array}$

Several children from both countries were confused about whether the Sun is living or not. For example:

\begin{tabular}{|c|c|}
\hline Interviewer & Is the Sun living? \\
\hline Student $^{\mathrm{C} 1}$ & e, but I'm not sure. It will become a white dwarf. \\
\hline Student ${ }^{\mathrm{A} 3}$ & and never thought about this thing. \\
\hline
\end{tabular}

Quiz item 3 focused on heredity and what causes a person to be born with curly hair or straight hair. The majority of children from both countries selected the correct response 'the type of hair their parents have'. A large number of children from the Chinese low socioeconomic school (C3) selected the incorrect answer, 'the type of hair their brothers and sisters have'. According the One Child Policy in China, rural residences are permitted to have 
more than one child but urban residences are permitted to have only one child. These children were, therefore, more likely to have brothers and sisters than urban children. It may be that this experience resulted in more children selecting the incorrect response because they have similar hair type to their brothers and sisters. Urban children in China rarely have brothers and sisters and are probably less likely to have had the experience that might result in them selecting the incorrect response.

Quiz item 4 probed children's understanding about which part of a plant takes in the most water. Most Australian children (93.3\%) selected the correct answer, 'the root'. Slightly more Chinese children, particularly children from the low SES school, incorrectly selected 'Part B (the leaves)'. Interviews revealed that children tended to correctly understand that leaves use water for photosynthesis, but incorrectly believed leaves take in the most water. The following interview excerpts illustrate this finding.

\begin{tabular}{|c|c|}
\hline Interviewer & Why do you think trees, flowers, and grass are living? \\
\hline Student $^{\mathrm{A3}}$ & They are living because they need water, sunlight, and they breathe. \\
\hline Interviewer & How do you know that they need water? \\
\hline Student $^{\mathrm{A3}}$ & $\begin{array}{l}\text { I got taught that in class. The root takes in the water and sends it to } \\
\text { the trunk and then the branches. The branches give water to the } \\
\text { leaves. Leaves have lines in the middle. }\end{array}$ \\
\hline
\end{tabular}

Interviewer Why do you think trees, flowers, and grass are living?

Student $^{\mathrm{C} 3} \quad$ Because they grow and they need sunlight and rain, otherwise they wither and die.

Interviewer How do trees take in the rain?

Student $^{\mathrm{C} 3}$ The rain falls on the leaves and then photosynthesis happens. I remember leaves also take a bit of water in the air.

\section{Children's Understanding of Earth Science}

Quiz items 5 to 8 probed children's understanding of Earth science. The percent correct response to these quiz items for all six cases are presented in Table 5. Responses to these items revealed a very similar profile for Chinese and Australian children's understandings in this domain, however, some divergence was evident. The Australian medium and low socioeconomic schools (A2 and A3) did better than the medium and low socio-economic Chinese schools (C2 and C3) on quiz item 5 about layers of the Earth. Students at the Australian medium socio-economic school (A2) also did better than the students at the medium socioeconomic Chinese school (C2) on quiz items 6 and 7 about the day/night cycle and the 
seasons on the Earth. The low socio-economic Australian school (A3) reported the lowest percentage of correctness on these two items.

\section{Insert Table 4 about here}

Quiz item 5 presented children with a picture showing the three main layers of the Earth and asked which layer was the hottest. The majority of Australian children gave the correct answer 'Layer C' (the innermost layer) and the average percentage of correctness on this item was 96.2\%, which was higher than TIMSS 1999 international average (82\%) for the Upper Grade (Grade 8). Slightly more Chinese children selected the incorrect response 'Layer A' (the outmost layer).

During the in-depth interviews, children were asked "What's the shape of the Earth?", "Can you draw a picture of the Earth?", "Can you stand on the top/bottom/sides/of the Earth?" and "Will you fall off?" These questions helped us to identify whether children conceptualized the Earth as a sphere or flat ground. It was found that although the majority of children from both countries knew the Earth is spherical in shape and showed some understanding of gravity, the majority couldn't organise their thinking into a coherent system to give appropriate causal explanations with these two concepts. This finding is consistent with previous research by Nussbaum and Novak (1976) and Vosniadou and Brewer (1992, 1994). For example, the interview excerpt shows that one student from the low SES school in China (C3) said the Earth was round like a ball but gave confounding explanations that oceans and islands are "in" the Earth while people are "on" the Earth.

\footnotetext{
Researcher What is the shape of the Earth?

Student $^{\mathrm{C} 3} \quad$ It's round like a ball.

Researcher Are the oceans and islands that you drew in the Earth, or on the Earth?

Student $^{\mathrm{C} 3} \quad$ In the Earth.

Researcher What about those people you drew? Are they in the Earth, or on the Earth?

Student $^{\mathrm{C} 3} \quad$ They are standing on the Earth.
}

Quiz item 6 and 7 focused on the cause of day and night and the main cause of the seasons on the Earth. Item 7 was selected from the TIMSS 1999 Science for the Grade 8 children and was a relatively challenging item, with only $26 \%$ of children internationally answering correctly. However, on average about half of the children from both countries answered correctly that 'The Earth rotates on its axis' explains the day and night cycle and that the 'Earth's axis is tilted' accounts for seasons. Children's explanations of the day and night cycle and the seasons depends on how they conceptualize the Earth, the Sun, and the 
Moon (Vosniadou \& Brewer, 1994). Interviews revealed that most children from both countries were able to give correct explanations for the day and night cycle as most of them have received instruction on this topic. Interestingly, the Australian children mentioned "time zone", "longitude", their traveling experience to Singapore, Malaysia or America and knowing people who live in England in their explanation of the day and night cycle. This phenomenon also was reported in the recent research by Author (Author, in press-a). For example:

Interviewer Why do we have day and night on the Earth?

Student $^{\mathrm{A} 3} \quad$ Because the Earth spins. There are northern hemisphere and southern hemisphere, just like England and Australia. When here is the day, there is the night.

Reasoning about the seasons on Earth was a challenging question for the sixth grade children. The Australian children more often mentioned that seasons occur on the Earth because the Earth is tilted so some part of the Earth is more exposed to the Sun. A number of children from the low socio-economic Chinese school (C3) attributed seasons to the Earth moving around the Sun or the Sun moving around the Earth, or they explicitly said that they didn't know. Several children in both countries expressed some understanding of the tilted axis, but had difficulty explaining the full phenomenon. For example:

\footnotetext{
Interviewer Why do we have seasons on the Earth?

Student $_{1}{ }^{\mathrm{C} 3} \quad$ When the Sun moves to this area, this area has light. Wherever there is light, there is summer. It is winter when there is no light.

Interviewer What about you?

Student ${ }_{2}{ }^{\mathrm{Cl}} \quad$......I don't know.

Interviewer What makes the seasons on Earth?

Student $^{\mathrm{A3}} \quad$ I think it's because the Earth tilted in its axis and it's got all the seasons. But I'm not sure how they come around.
}

Quiz item 8 probed children's conceptual understanding of gravity. Children were presented with a diagram with a person holding a ball while standing at three different places on Earth. Children were asked to choose which of four diagrams best describe the direction the dropped ball would fall at the three different positions. Almost the same percentage of Chinese children (71.4\%) and Australian children (70.5\%) selected the correct diagram showing that the ball would always drop towards the center of the Earth. Internationally, 70\% 
of Grade 8 children answered this item correctly in TIMSS 2003 (Table 4). During the interview, the Chinese and Australian sixth graders gave similar answers regarding where a dropped ball would go and where gravity is. Fourteen out of twenty Chinese 6th graders responded that the ball would fall towards the centre of the Earth and drew arrows pointing towards the Earth's center. Eight out of eighteen Australian 6th graders responded that the ball would fall towards the Earth or the center of the Earth because of gravity and the rest of the children simply answered that the ball would go straight to the ground without mentioning gravity.

\section{Children's Understanding of Physical Science}

In the section on physical science from quiz item 9 to item 12, children were tested about their conceptual understanding and reasoning about floating and sinking. The percent correct response for these items in all six cases are presented in Table 5. In general, the Australian sixth graders displayed relative strength in understanding of floating and sinking. Divergence was most notable between the medium socio-economic schools (C2 and A2) and the low SES schools (C3 and A3) for quiz item 10 about floating objects and quiz item 12 about floating ice cubes.

\section{Insert Table 5 about here}

Quiz items 9 and 10 presented children with pictures of three objects of the same shape and size floating and sinking at different levels in water. Children were asked to compare the weight of the three objects. Most Chinese and Australian children from the high SES schools gave the correct responses to both quiz item 9 and 10 (Table 5).

Quiz item 11 presented children with a picture showing a block of wood floating in fresh water. Children were asked to choose which of four alternatives would best describe the position of this wood block in salt water. This item was selected from TIMSS 1995 and it was a relatively difficult item with only $34 \%$ of eighth grade students internationally answering correctly. On average, $38.1 \%$ of children from the Australian cases gave the correct answer, with small differences among the high, medium and low SES schools. However, the percentage of correctness varied considerably among the three schools in China, with $87 \%$ of children from the high SES school answering correctly, which was over 50\% higher than the international average, and only $27.3 \%$ of children from the medium SES school giving the correct answer. To answer correctly, children had to demonstrate knowledge of density by selecting the picture showing that the wood block will float higher in salt water than it does in 
fresh water. An interview with the science teacher in the Chinese high SES school indicated that those 6th graders had been doing many hands-on activities as proposed in the science curriculum and text books. It is likely that the children's experience of comparing object's floating and sinking in different fluids may have helped them to answer this item correctly.

Quiz item 12 probed the children's understanding of flotation of ice cubes of different sizes in water. On average, $61 \%$ of Australian children gave the correct response that all ice cubes would float in water regardless of their size. Similar to their performance on quiz item 11, the percent correct response to this item of Chinese children from the three different schools varied considerably. Divergence is clear with Australian children from the medium and low SES schools performing considerably better than their counterparts from the paired schools on this item (Table 5). Interviews revealed that experience with water-based activities made a difference to students' understanding of floating and sinking, for example:

\begin{tabular}{|c|c|}
\hline Interviewer & $\begin{array}{l}\text { What would happen if we put a } 10 \text {-cent coin and } \\
\text { coin into water at the same time? }\end{array}$ \\
\hline Student $^{\mathrm{A} 2}$ & $\begin{array}{l}\text { I tested it when I was at home. I got coins and I put } \\
\text { water and they sank straight away. }\end{array}$ \\
\hline Interviewer & What would happen if we put an apple into water? \\
\hline Student $^{\mathrm{A3}}$ & Apples can actually float. \\
\hline Interviewer & How do you know? \\
\hline Student $^{\mathrm{A3}}$ & I did apple bobbing. \\
\hline
\end{tabular}

Our in-depth interviews about criteria to determine if an object would float or sink when put in water indicated that Grade 6 children from both countries said an object would float if it is "lighter than the water", if it "has more buoyancy", if it "has air in it", or if it "has lighter density than water". Children from both counties said an object would sink if it is "heavier than water", if it "doesn't have air in it", if it "is made of [a certain kind of material such as] metal", or if it is "denser than water". However, children's understanding of density and buoyancy were not complete or scientific and indicated they had memorized seemingly scientific responses and definitions. For example:

\begin{tabular}{|c|c|}
\hline Interviewer & What would happen if we put a cardboard box into water? \\
\hline Student $^{\mathrm{C} 3}$ & $\begin{array}{l}\text { It would float, because the cardboard box is light and it has } \\
\text { buoyancy. }\end{array}$ \\
\hline Interviewer & What is buoyancy? \\
\hline Student $^{\mathrm{C} 3}$ & $\begin{array}{l}\text { Buoyancy is a force to keep things floating on the surface } \\
\text { of the water. }\end{array}$ \\
\hline
\end{tabular}




\section{Discussion}

Previously reported research (Author, in press-b) revealed that the early childhood curriculum in science in Australian schools did not show any benefit for the third grade children with regard to their conceptual understanding of science compared with the Chinese children who did not participate in a science curriculum from the paired schools. The study reported in this paper was designed to investigate whether the grounding in early childhood science education in Australia resulted in any difference in children's conceptual understanding of science as they progress towards the end of elementary school.

The findings revealed that participating Grade 6 children from the schools with high socio-economic status from China and Australia demonstrated similar profiles in their understanding of science. Any potential advantage of three extra years of early childhood science education was not evident for the children in the Australian high socio-economic case study school (A1) compared with the children in the Chinese high socio-economic school (C1). Conversely, it can be said that the findings revealed no evidence of disadvantage as a result of not having a formal early childhood science education for the Chinese children attending the high socio-economic school. Interviews with the Chinese high SES school children revealed that they had sufficient access to science books and resources at home, and that their parents actively teach them science, for example, by asking them to design an experiment or by discussing scientific topics. All these factors possibly help to compensate their lack of formal science education at an early age.

Divergence in children's performance on the science quiz and interviews was evident between the Chinese and Australian medium SES schools, as well as between the low SES schools. Both science quiz and in-depth interviews indicated that the participating Australian children from the medium and low SES schools (A2 and A3), in general, had better understanding of life science, Earth science and physical science than the Chinese children from the paired schools ( $\mathrm{C} 2$ and $\mathrm{C} 3$ ). The findings raised the question: why did the Australian Grade 6 children from the medium and low SES schools have better conceptual understanding of science than the Chinese children from the paired schools? There are a number of possible explanations for this finding of which we will consider two, impoverished domain specific knowledge and quality pedagogy.

\section{Impoverished Domain Specific Knowledge}


The first possible explanation for the observed divergence is that the early science education for the Australian children in the medium and low SES schools provided the students with grounding in domain specific scientific knowledge. This grounding was not initially evident in the third graders (Author, in press-b) but, as indicated by the findings presented in this paper, this grounding became more evident towards the end of elementary school. This is consistent with the justification for an early childhood science curriculum promoted in the Western Australian Curriculum Framework (Curriculum Council, 1998, p. 231), that children's knowledge can be "built on in the future" and that "during the early years, curriculum experiences should be designed to give young children frequent opportunities to begin exploring concepts, which provide the foundation for later understandings" (p. 232).

The view that early childhood instruction can make a difference for children in their later years is supported by science education research (Metz, 1995, 1997; Bliss, 1995). Metz (1995) asserted that rather than using Piagetian levels of development to indicate whether children are 'developmentally ready' for science instruction and underestimating their capacities, teachers and educators should be thinking about scaffolding children's potential through high quality science instruction. Metz (1997) emphasized the importance of acknowledging that children need content knowledge in a specific domain to be able to participate in inquiry and scientific reasoning. For example, if children do not know that plants grow from seeds or that plants take in gasses to 'breathe' (i.e. domain specific knowledge), it is almost impossible for them to correctly classify living and non-living things (a process of reasoning). Further, knowing certain domain specific knowledge helps children to participate in other reasoning processes such as drawing analogies between living things they tend to know well, like humans and dogs, and less familiar living things, such as plants (Author, 2004). Differentiating living from non-living things and plants from animals are ideas taught in early childhood science education that require children to be able to classify using more than one criterion. According to Metz's argument, if young children, at about five years of age who are predominantly at the Piagetian pre-operational developmental stage, learn content knowledge about plants, this will give them access to the domain specific knowledge needed for reasoning processes such as classification and analogy creating that are characteristic of the higher order Piagetian concrete operation developmental level. The development of domain specific knowledge and more general reasoning patterns are, therefore, intimately entwined and it is likely that delaying the introduction of one will inhibit the development of the other. It is possible that the lack of early childhood science curriculum in the medium and low socio-economic schools in China resulted in comparatively 
impoverished domain-specific knowledge compared with the children in the Australian schools that, in turn, led to underdeveloped scientific reasoning abilities.

\section{Quality Pedagogy}

Another possible explanation for the divergence in the medium and low SES schools in China and Australia is the quality of the classroom teaching and learning activities. Schools with high socio-economic status have better and richer teaching resources and put emphasis on the quality of pedagogy, as well as the quality of teachers' professional development. Research in both countries reveals that schools with medium or low socio-economic status more often have limited teaching resources and facilities, fewer specialist science teachers, and put less emphasis on the implementation of science education (Cao, 2005; Goodrum, et al., 2001; Hu, et al., 2007; Y. F. Li, 2007; Z. C. Li, 2006; Perry \& McConney, 2010; Tian \& Guo, 2009).

The relative strengths in conceptual understanding of science demonstrated by the Australian Grade 6 children from the medium and low SES schools may be attributed to the focus in Australian science classrooms on scientific inquiry learning activities. Referred to as “Confucian-heritage" cultures (Biggs, 1996, p. 46), classrooms in China are known for their large class sizes often with more than 40 children, highly authoritarian learning climate, expository teaching methods, and examination-oriented learning (Aldridge, et al., 1999; Biggs, 1996; Chang \& Mao, 1999; Stevenson \& Stigler, 1992). Australian classrooms, however, are student-centered with small class sizes ranging from 13 to 32 students. A large number of science lessons include practical activities. Australian science teachers tend to distribute equal time to whole-class instruction and group work. Moreover, they spend a large proportion of the class time presenting and discussing scientific concepts, experimental procedures, and connecting scientific knowledge to real life issues (Goodrum, et al., 2001; Lokan, et al., 2006; Murcia, 2007). The results from this study raise questions about the impact of classroom inquiry and learning activities on children's conceptual understanding of science. More research is needed to explore how scientific inquiry and other science learning activities are enacted in Chinese and Australian elementary science classrooms to be able to fully understand the findings presented in this paper.

\section{Implications and Limitations}

In this section we make speculative suggestions with regard to the educational implications of the findings of this study and the study of third grade children in the same schools (Author, in press-b). This research provides support for the reform of the current national science 
curriculum in China, Science Curriculum Standards (3rd-6th Grades) of Full-time Compulsory Education. We suggest that first and second grade children should be included in the elementary science curriculum, as it is possible that the lack of early childhood science education placed the participating children from case study schools with medium and low socio-economic status at a disadvantage in their science learning when they were tested towards the end of elementary school. The findings give insight into the effects and possible causes of the current lack of early childhood science education, but more research is needed to verify the findings in other contexts within these countries and also in other countries that have different approaches to early childhood science education.

There are a number of limitations of this study that need to be mentioned. First, considerable care was taken with the selection of the case studies to make sure that paired schools were similar and comparable in the demography, size and socio-economic status. The results from the third grade case studies (Author, in press-b) showed that there was no statistical difference in science quiz scores between paired schools of similar socio-economic status. The data supported the assertion that the schools were appropriately matched. However, the cross sectional nature of the sample of Grade 3 and Grade 6 students may mean that the differences observed in the Grade 6 case studies and discussed in this paper are due to unobserved or non-speculated factors. A longitudinal method using the same children in Grade 3 and then three years later in Grade 6 would have been ideal but was not possible given the time and financial constraints of the research program.

A second limitation of this research is that there was no way of ascertaining the quantity and quality of the science curriculum in the schools in the years prior to the implementation of the case studies. While interviews with the principals, collection of school planning documents, and interviews and observations with current teachers indicated that teaching practices were consistent with the Chinese and Australian curricula, it is possible that in previous years other practices were in place. This also may have influenced the findings. Further, we want to emphasize that while the case study methodology was appropriate for this research, it is not appropriate to generalize the findings and make assumptions about other schools and other children in these countries or other countries. The detailed information provided, however, enables a process of transferability (Guba \& Lincoln, 1989) so that readers may apply the knowledge developed to educational contexts familiar to them.

Finally, this paper reports the participating Chinese and Australian sixth graders' conceptual understanding of science through a science quiz and in-depth interview. Future 
studies about whether the children's qualitative understandings of scientific concepts indicate any cultural differences, and different approaches to science teaching in the Chinese and Australian sixth grade classrooms and the impact on children's conceptual understanding of science are needed.

\section{References}

Anning, A., Cullen, J. \& Fleer, M. (2009). Research contexts across cultures. In A. Anning, J. Cullen \& M. Fleer (Eds.), Early childhood education: Society and culture, (pp. 1- 24, $2^{\text {nd }}$ edn.). London, Sage.

Aldridge, J. M., Fraser, B. J., \& Huang, T. C. (1999). Investigating classroom environments in Taiwan and Australia with multiple research methods. Journal of Educational Research, 93(1), 48-61.

Anderson, D., Lucas, K. B., \& Ginns, I. S. (2000). Development of knowledge about electricity and magnetism during a visit to a science museum and related post-visit activities Science Education, 84, 658-679.

Appleton, K. (2007). Elementary science teaching. In S. K. Abell \& N. G. Lederman (Eds.), Handbook of research on science education (pp. 493-536). Mahwah, NJ: Lawrence Erlbaum.

Australian Curriculum Assessment and Reporting Authority. (2011). The Australian curriculum: Science. Retrieved May 20, 2011, from http://www.australiancurriculum.edu.au/Science

Australian Science Technology and Engineering Council. (1997). Foundations for Australia's future: Science and technology in primary schools. Canberra: Australian Government Publishing Service.

Author. (2004). Journal of Research in Science Teaching.

Author. (2005). Science Education.

Author. (2007a). (1st ed.). Crows Nest: Allen \& Unwin.

Author. (2007b). Paper presented at the 17th European Early Childhood Education Research Association Annual Conference.

Author. (2007c). International Journal of Science Education.

Author. (in press-a). Research in Science Education.

Author. (in press-b). International Journal of Science Education.

Baddock, M., \& Bucat, R. (2008). Effectiveness of a classroom chemistry demonstration using the cognitive conflict strategy. International Journal of Science Education, 30(8), 1115-1128.

Biggs, J. B. (1996). Western misconceptions of the confucian-heritage learning culture. In D. A. Watkins \& J. B. Biggs (Eds.), The Chinese learner: cultural, psychological and contextual influences (pp. 45-68). Hong Kong: Comparative Education Research Centre.

California Department of Education. (2011). A look at kindergarten through Grade 6 in California public schools. Retrieved 16 June, 2011, from http://www.cde.ca.gov/ci/cr/cf/allfwks.asp

Campbell, C., \& Tytler, R. (2007). Views of student learning. In Author (Ed.), The art of teaching primary science (pp. 23-42). Crows Nest: Allen \& Unwin.

Cao, W. D. (2005). Thoughts of the current situation of science teaching in primary schools. Science Lesson, 2, 46 [in Chinese].

Chang, C. Y., \& Mao, S. L. (1999). Comparison of Taiwan science students' outcomes with inquirygroup versus traditional instruction. Journal of Educational Research, 92(6), 340-346.

Chen, Q. (2004a). Reflection upon the current primary science education. Beijing Education, 7, 15-17 [in Chinese].

Chen, Q. (2004b). Scientific inquiry and early science education. Journal of the Chinese Society of Education, 10, 49-52 [in Chinese].

Cohen, J. (1988). Statistical power analysis for the behavioral sciences (2nd ed.). Hillsdale, NJ: Erlbaum. 
Creswell, J. W. (2003). Research design: Qualitative, quantitative and mixed methods approaches (2nd ed.). California: Sage Publications, Inc.

Curriculum Council Western Australia. (1998). Curriculum Framework Learning Statement for Science. $\quad$ Retrieved 20 March, 2009, from http://www.curriculum.wa.edu.au/internet/Years K10/Curriculum Framework

Department of Elementary Education. (2008). Grade 1-9 science and technology curriculum guidelines. Retrieved 13 May, 2011, from http://teach.eje.edu.tw/9CC2/9cc 97.php [in Chinese]

Ding, Z. Y. (1984). Congnitive development of early primary children in China. Acta Psychologica Sinica(2), 139-146.

Fan, Q., \& Zhao, J. (2002). A survey of Chinese primary students' science literacy: A report from National Primary Science Curriculum Board. Science Lesson, 6, 16-18 [in Chinese].

Fensham, P. J. (1999). International success, but is it science? Identifying strengths and weaknesses in Australian primary school science from TIMSS and other data. Australian Science Teachers' Journal, 45(2), 39-44.

Fleer, M. (1994). Determining children's understanding of electricity. Journal of Educational Research, 87(4), 248-253.

Georghiades, P. (2006). The role of metacognitive activities in the contextual use of primary pupils' conceptions of science. Research in Science Education, 36, 29-49.

Goodrum, D., Hackling, M., \& Rennie, L. (2001). The status and quality of teaching and learning of science in Australian schools. Canberra: Department of Education, Training and Youth Affairs

Greenfield, D. B., Jirout, J., Dominguez, X., Greenberg, A., Maier, M., \& Fuccilo, J. (2009). Science in the preschool classroom: A programmatic research agenda to improve science readiness. Early Education and Development, 20(2), 238-264.

Guba, E. G., \& Lincoln, Y. S. (1989). Fourth generation evaluation. Newbury Park: Sage Publications.

Hao, J. H. (2002). Illustrations to science curriculum standards (3-6 grades) of full-time compulsory education (trial version). [in Chinese]. Wuhan: Hubei Education Press.

Harlen, W. (1997). Primary teachers' understanding in science and its impact in the classroom. Research in Science Education, 27(3), 323-337.

Harrison, A., Grayson, D. J., \& Treagust, D. F. (1999). Investigating a Grade 11 student's evolving conceptions of heat and temperature. Journal of Reseach In Science Teaching, 36(1), 55-87.

Hickey, R. (2007). Understanding how children learn science. In Author (Ed.), The art of teaching primary science (pp. 43-61). Crows Nest, NSW: Allen\&Unwin.

Hu, W. P., Han, Q., \& Liu, J. W. (2007). Investigation into and thoughts of the current situation of the implementation of new curriculum of science in the primary schools. Theory and Practice of Education, 27(3), 58-63 [in Chinese].

Li, F. G. (2007). Students' understanding of pressure: Preliminary findings. Retrieved February 15, 2009, from http://se.risechina.org/yisy/200707/1838.html [in Chinese].

Li, H. (2004). A brief history of primary science curriculum reform in China. [in Chinese]. Beijing: People's Education Press

Li, Y. F. (2007). Enhancing the reform of rural primary science education Educational Science and Research, 8, 33-35 [in Chinese].

Li, Z. C. (2006). The status of science subject in primary schools. Science Lesson, 9, 38-39 [in Chinese].

Liu, M. G. (1998). Study on the reform of primary nature curriculum in China. [in Chinese]. Wuhan: Hubei Education Press.

Lokan, J., Hollingsworth, H., \& Hackling, M. W. (2006). Teaching science in Australia: Results from the TIMSS 1999 video study. Retrieved 9 February, 2010, from http://www.acer.edu.au/documents/TIMSS TVidSciAujzMar06FINAL2.pdf

Luo, H. J. (2006). Case study on students' understanding of floating and sinking: Preliminary findings. Retrieved February 15, 2009, from http://se.risechina.org/yjsy/200608/1737.html [in Chinese]. 
Luo, P., Wang, M. Y., \& Liang, X. (2009). On the "Force and Movement" understanding of children aged 5-6 years old. Studies in Preschool Education, 11, 26-31 [in Chinese].

Luo, Y. W. (2006). Students' understanding of expansion and contraction. Retrieved February 15, 2009, from http://se.risechina.org/yjsy/200611/1765.html [in Chinese].

Metz, K. E. (1995). Reassessment of developmental constraints on children's science instruction. Review of Educational Research, 65(2), 93-127.

Ministry of Education. (2001). An outline of curriculum reform of basic education. Journal of Subject Education, 7, 1-5 [in Chinese].

Moore, T., \& Harrison, A. (2004). Floating and Sinking : Everyday Science in Middle School. Paper presented at the Conference of the Australian Association for Research in Education, Melbourne.

Mullis, I. V. S., Martin, M. O., Olson, J. F., Berger, D. R., Milne, D., \& Stanco, G. M. (2008). TIMSS 2007 Encyclopedia: A guide to mathematics and science education around the world. Volume $1 \mathrm{~A}-$

L. Retrieved May 14, 2009, from http://timss.bc.edu/TIMSS2007/PDF/T07 Enc V1.pdf

Murcia, K. (2007). Science for the 21st century: Teaching for scientific literacy in the primary classroom. Teaching Science, 53(2), 16-19.

Nussbaum, J., \& Novak, J. D. (1976). An assessment of children's concepts of the Earth utilizing structured interviews. Science Education, 60(4), 535-550.

Nuthall, G. (1999). The way students learn: Acquiring knowledge from an integrated science and social studies unit. The Elementary School Journal, 99(4), 303-341.

Olson, J. F., Martin, M. O., \& Mullis, I. V. S. (2008). TIMSS 2007 technical report. Retrieved 14 May, 2009, from http://timss.bc.edu/TIMSS2007/techreport.html

Pattie, I., \& Groves, R. (1993). What do they know? The understanding of science and technology by children in their last year of primary school in Australia: Australian Government Publishing Service.

Perry, L., \& McConney, A. (2010). School socio-economic composition and student outcomes in Australia: Implications for educational policy. Australian Journal of Education, 54(1), 72-85.

Piaget, J. (1930). The child's conception of physical causality. London: Routledge and Kegan Paul.

Punch, K. F. (2005). Introduction to social research-quantitative and qualitative approaches (2nd ed.). London: Sage Publications.

Qu, T. H., \& Wang, J. (2000). The development and enlightenment from science education in modern China. Journal of Northeast Normal University (Philosophy and Social Science), 6, 8995 [in Chinese].

Quek, G., Goh, K. H., Yen, Y. P., Liu, Y. M., Tan, Q. L., Chin, T. Y., et al. (2008). Singapore. TIMSS 2007 Encyclopedia: A guide to mathematics and science education around the world. Volume $2 \mathrm{M}$ $Z$ and benchmarking participants. Retrieved 7 June, 2011, from http://timss.bc.edu/TIMSS2007/PDF/T07 Enc V2.pdf

Saçkes, M., Trundle, K. C., Bell, R., \& O'Connell, A. (2011). The influence of early science experience in kindergarten on children's immediate and later science achievement: Evidence from the early childhood longitudinal study. Journal of Research in Science Teaching, 48(2), 217-235.

Stevenson, H. W., \& Stigler, J. W. (1992). The learning gap : Why our schools are failing and what we can learn from Japanese and Chinese education. New York: Summit Books.

Thomson, S. (2006). Science achievement in Australia: Evidence from national and international surveys. Retrieved from http://www.acer.edu.au/research conferences/2006.html

Thomson, S., Ainley, J., \& Nicholas, M. (2007). Australia. TIMSS 2007 Encyclopedia: A guide to mathematics and science education around the world. Volume 1 A-L. Retrieved 14 May, 2009, from http://timss.bc.edu/TIMSS2007/PDF/T07 Enc V1.pdf

Thomson, S., \& De Bortoli, L. (2008). Exploring scientific literacy: How Australia measures up. Retrieved September 30, 2010, from http://www.acer.edu.au/documents/PISA2006 Report.pdf 
Thomson, S., \& Fleming, N. (2004). Examining the evidence: Science achievement in Australian schools in TIMSS 2002. Retrieved 30 September, 2010, from http://www.acer.edu.au/timss/data-and-reports

Thomson, S., Wernert, N., Underwood, C., \& Nicholas, M. (2008). TIMSS 2007: Taking a closer look at mathematics and science in Australia. Retrieved 6 October, 2010, from http://www.acer.edu.au/documents/TIMSS 2007-AustraliaFullReport.pdf

Tian, S. C., \& Guo, Y. J. (2009). Science learning contexts in primary and secondary schools China Education, 11, 58-60 [in Chinese].

Vosniadou, S., \& Brewer, W. F. (1992). Mental models of the Earth: A study of conceptual change in childhood. Cognitive Psychology, 24(4), 535.

Vosniadou, S., \& Brewer, W. F. (1994). Mental models of the day/night cycle. Cognitive Science, 18(1), 123-183.

Wan, D. S. (2007). Students' understanding of friction: Priliminary findings (in Chinese). Retrieved March 2, 2009, from http://se.risechina.org/yisy/200707/1842.html

Wei, Y. (2008a). Minutes of the first board meeting on proposed national primary science curriculum. Retrieved October 8, 2008, from http://nsse.handsbrain.com/article.php/296 [in Chinese].

Wei, Y. (2008b). Recovering science education in primary Year 1 and Year 2. Retrieved October, 8, 2008, from http://nsse.handsbrain.com/article.php/36 [in Chinese]

White, R., \& Gunstone, R. (1992). Probing understanding. London: The Falmer Press.

Xiang, Y. H. (2006). Students' ability of controlling variables: Priliminary findings. Retrieved February 15, 2009, from http://se.risechina.org/yjsy/200610/1756.html [in Chinese].

Yang, H. (2004). Piaget's theory has great sense to the curriculum designing. Journal of Zhengzhou Institute of Aeronautical Industry Management (Social Science Edition), 23(5), 79-81.

Yin, R. K. (2003). Case study research: design and methods (3rd ed.). California: Sage Publications $\mathrm{Yu}$, X. L. (1997). Piaget's theory and science education (in Chinese). Educational Research, 1, 66-71.

Zhang, L. J., \& Fang, F. X. (2005a). Effect of relevant training on understanding of plant reproduction in preschoolers aged 5 to 6 . Chinese Mental Health Journal, 19(9), 579-582.

Zhang, L. J., \& Fang, F. X. (2005b). Understanding of naive theory of biology for animal reproduction in 4-to-7-year-olds. Acta Psychological Sinica, 37(5), 613-622.

Zhang, Q. M. (2006). Students' scientific hypotheses on lever balance. Retrieved February 15, 2009, from http://se.risechina.org/yjsy/200609/245.html [in Chinese].

Zhong, Q. Q. (2002). Congnitive issues in science education (in Chinese). Global Education Outlook, $31(2), 6-10$.

Zhu, L. Q., \& Fang, F. X. (2005). Children's understanding of aging. Acta Psychological Sinica, 37(3), 335-340.

Zhuang, X. Z. (2001). Piaget's stage theory and educational reform (in Chinese). Journal of Changzhou Teachers College of Technology, 7(3), 8-11.

Table 1. Participating third graders' mean scores on the science quiz

\begin{tabular}{ccccccccc}
\hline $\begin{array}{c}\text { Chinese } \\
\text { Schools }\end{array}$ & $\mathrm{N}$ & $\begin{array}{c}\text { Mean } \\
\text { Score }\end{array}$ & SD & $\begin{array}{c}\text { Australian } \\
\text { Schools }\end{array}$ & N & Mean & SD & $\begin{array}{c}\text { T-test } \\
\text { Score }\end{array}$ \\
\hline C1 (high SES) & 51 & 7.37 & 2.09 & A1 (high SES) & 34 & 7.65 & 1.91 & 0.14 \\
C2 (med SES) & 37 & 6.76 & 1.21 & A2 (med SES) & 37 & 6.32 & 1.90 & 0.28 \\
C3 (low SES) & 47 & 5.30 & 1.57 & A3 (low SES) & 49 & 5.82 & 1.63 & 0.32 \\
Total & 135 & 6.48 & 1.92 & Total & 120 & 6.49 & 1.94 & 0.005 \\
\hline
\end{tabular}


Table 2. Participating sixth graders' mean scores on the science quiz

\begin{tabular}{ccccccccc}
\hline $\begin{array}{c}\text { Chinese } \\
\text { Schools }\end{array}$ & $\mathrm{N}$ & $\begin{array}{c}\text { Mean } \\
\text { Score }\end{array}$ & SD & $\begin{array}{c}\text { Australian } \\
\text { Schools }\end{array}$ & $\mathrm{N}$ & $\begin{array}{c}\text { Mean } \\
\text { Score }\end{array}$ & SD & $\begin{array}{c}t \text {-test } \\
d \text { value }\end{array}$ \\
\hline C1 (high SES) & 46 & 9.89 & 1.72 & A1 (high SES) & 31 & 9.84 & 1.29 & 0.03 \\
C2 (med SES) & 44 & 8.27 & 1.98 & A2 (med SES) & 34 & 9.56 & 1.69 & 0.69 \\
C3 (low SES) & 50 & 7.60 & 1.86 & A3 (low SES) & 40 & 8.55 & 1.87 & 0.51 \\
Total & 140 & 8.56 & 2.08 & Total & 105 & 9.26 & 1.74 & 0.36 \\
\hline
\end{tabular}

Table 3. Percent correct response for quiz items 1 to 4 (life science)

\begin{tabular}{|c|c|c|c|c|}
\hline \multirow{3}{*}{ Concept } & \multicolumn{4}{|c|}{ Percent correct response (\%) for quiz items $1-4$} \\
\hline & Q1 & Q2 & Q3 & Q4 \\
\hline & Living/non-living & Living/non-living & $\begin{array}{l}\text { Inheritance of } \\
\text { curly hair }\end{array}$ & $\begin{array}{l}\text { Plant roots and } \\
\text { water absorption }\end{array}$ \\
\hline \multicolumn{5}{|l|}{ Chinese children } \\
\hline $\mathrm{C} 1(\mathrm{n}=46)$ & 100.0 & 100.0 & 91.3 & 89.1 \\
\hline$C 2(n=44)$ & 90.9 & 81.8 & 97.7 & 86.4 \\
\hline$C 3(n=50)$ & 86.0 & 80.0 & 68.0 & 74.0 \\
\hline Total $(n=140)$ & 92.1 & 87.1 & 85.0 & 82.9 \\
\hline \multicolumn{5}{|l|}{ Australian children } \\
\hline $\mathrm{A} 1(\mathrm{n}=31)$ & 100.0 & 100.0 & 93.5 & 90.3 \\
\hline A2 $(n=34)$ & 97.1 & 100.0 & 88.2 & 100.0 \\
\hline A3 $(n=40)$ & 87.5 & 90.0 & 90.0 & 90.0 \\
\hline Total $(n=105)$ & 94.3 & 96.2 & 90.5 & 93.3 \\
\hline $\begin{array}{l}\text { TIMSS International } \\
\text { average for Grade } 8\end{array}$ & 74.0 & N/A & N/A & N/A \\
\hline
\end{tabular}

Note. $\mathrm{N} / \mathrm{A}=$ not available 
Table 4. Percent correct response for quiz items 5 to 8 (Earth science)

\begin{tabular}{lllll}
\hline \multicolumn{4}{c}{ Concept } & \multicolumn{2}{l}{$\begin{array}{l}\text { Percent correct response (\%) to quiz items 5-8 } \\
\text { Layers of the } \\
\text { Earth }\end{array}$} & $\begin{array}{l}\text { Q6 } \\
\text { Cause of } \\
\text { day/night cycle }\end{array}$ & $\begin{array}{l}\text { Q7 } \\
\text { Cause of } \\
\text { seasons }\end{array}$ & $\begin{array}{l}\text { Q8 } \\
\text { Gravity }\end{array}$ \\
\hline Chinese children & & & & \\
C1 $(\mathrm{n}=46)$ & 89.1 & 54.3 & 52.2 & 84.8 \\
C2 $(\mathrm{n}=44)$ & 84.1 & 43.2 & 52.3 & 68.2 \\
C3 $(\mathrm{n}=50)$ & 76.0 & 44.0 & 54.0 & 62.0 \\
Total $(\mathrm{n}=140)$ & 82.9 & 47.1 & 52.9 & 71.4 \\
Australian children & & & & \\
A1 $(\mathrm{n}=31)$ & 100.0 & 58.1 & 64.5 & 80.6 \\
A2 $(\mathrm{n}=34)$ & 97.1 & 64.7 & 64.7 & 70.6 \\
A3 $(\mathrm{n}=40)$ & 92.5 & 32.5 & 27.5 & 62.5 \\
Total (n=105) & 96.2 & 50.5 & 50.5 & 70.5 \\
TIMSS International & 82.0 & 44.0 & 26.0 & 70.0 \\
average for Grade 8 & & & & \\
\hline Note N/A = not available & & &
\end{tabular}

Table 5. Percent correct response for quiz items 9 to 12 (physical science)

\begin{tabular}{|c|c|c|c|c|}
\hline \multicolumn{5}{|c|}{ Percent correct response (\%) for quiz items $9-12$} \\
\hline Concept & Q9 & Q10 & Q11 & Q12 \\
\hline & $\begin{array}{l}\text { Floating/sinking } \\
\text { objects }\end{array}$ & $\begin{array}{l}\text { Floating/sinking } \\
\text { objects }\end{array}$ & $\begin{array}{l}\text { Floating in salt } \\
\text { water }\end{array}$ & Floating ice cubes \\
\hline \multicolumn{5}{|l|}{ Chinese children } \\
\hline $\mathrm{C} 1(\mathrm{n}=46)$ & 87.0 & 93.5 & 87.0 & 60.9 \\
\hline$C 2(n=44)$ & 88.6 & 65.9 & 27.3 & 40.9 \\
\hline $\mathrm{C} 3(\mathrm{n}=50)$ & 84.0 & 68.0 & 40.0 & 26.0 \\
\hline Total $(n=140)$ & 86.4 & 75.7 & 51.4 & 42.1 \\
\hline \multicolumn{5}{|l|}{ Australian children } \\
\hline A1 $(n=31)$ & 100.0 & 96.8 & 32.3 & 67.7 \\
\hline A2 $(n=34)$ & 85.3 & 85.3 & 41.2 & 61.8 \\
\hline A3 $(n=40)$ & 97.5 & 90.0 & 40.0 & 55.0 \\
\hline Total $(n=105)$ & 94.3 & 90.5 & 38.1 & 61.0 \\
\hline $\begin{array}{l}\text { TIMSS International } \\
\text { average for Grade } 8\end{array}$ & N/A & N/A & 34.0 & N/A \\
\hline
\end{tabular}

Note. $\mathrm{N} / \mathrm{A}=$ not available 


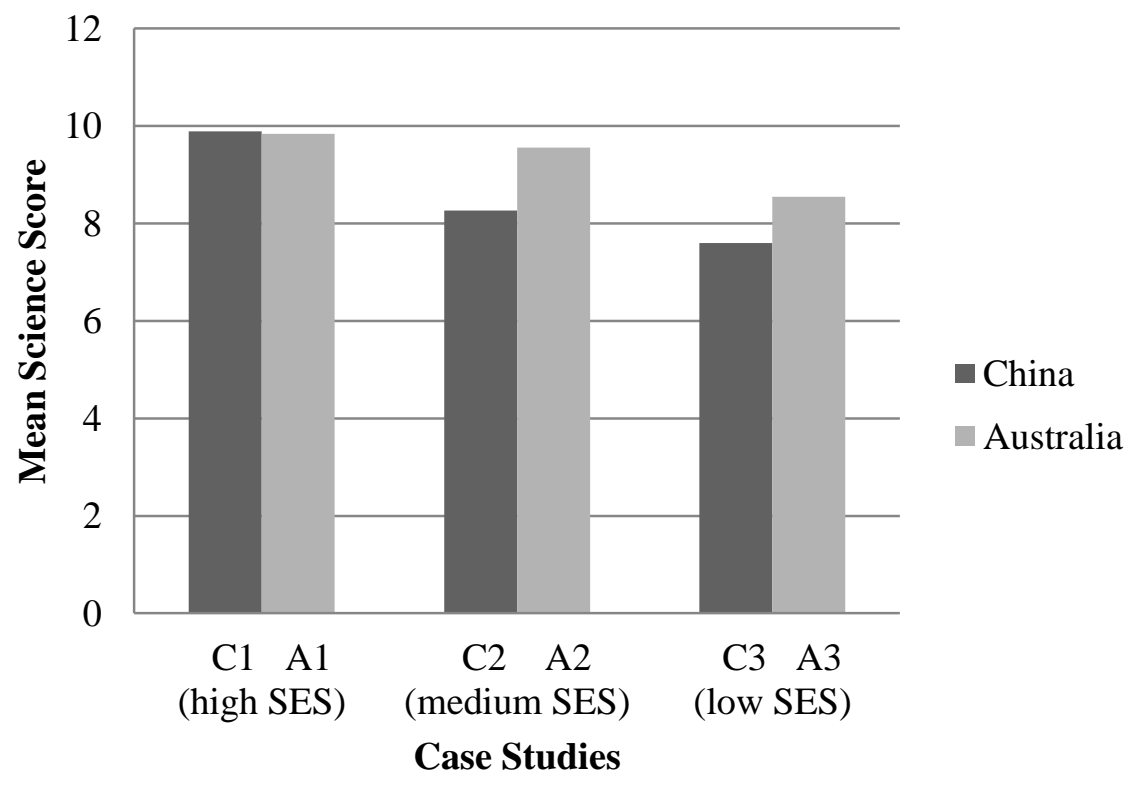

Figure 1. Chinese and Australian sixth graders' mean scores on the science quiz 